Anal ysi s of a waf er bonded $\mathrm{Ge} / \mathrm{Si}$ het er oj uncti on by transmi ssi on el ect ron mi cr oscopy

\begin{tabular}{|c|c|}
\hline 著者 & $\begin{array}{ll}\text { Kanbe H r oshi, M yaj i Nasayuki, Hi rose Nami, } \\
\mathrm{N} \mathrm{tta} \mathrm{Nori} \mathrm{ko,} \mathrm{Tani} \mathrm{waki} \mathrm{Nasaf} \mathrm{umi}\end{array}$ \\
\hline $\begin{array}{l}\mathrm{j} \text { our nal or } \\
\text { publ i cat } \mathrm{i} \text { on } \mathrm{title}\end{array}$ & Appl i ed Physi cs Letters \\
\hline vol une & 91 \\
\hline nunber & 14 \\
\hline page $r$ ange & $142119-1-142119-3$ \\
\hline year & 2007-10-04 \\
\hline URL & ht t p: //hdl . handl e. net /10173/593 \\
\hline
\end{tabular}




\title{
Analysis of a wafer bonded Ge/Si heterojunction by transmission electron microscopy
}

\author{
Hiroshi Kanbe, ${ }^{\text {a) }}$ Masayuki Miyaji, and Mami Hirose \\ Kochi University of Technology, Tosayamada-cho, Kami-shi, Kochi 782-8502, Japan \\ Noriko Nitta \\ Kyoto University Research Reactor Institute, Kumatori-cho, Sennan-gun, Osaka 590-0494, Japan \\ Masafumi Taniwaki \\ Kochi University of Technology, Tosayamada-cho, Kami-shi, Kochi 782-8502, Japan
}

(Received 27 May 2007; accepted 19 September 2007; published online 4 October 2007)

\begin{abstract}
A wafer-bonded $\mathrm{Ge} / \mathrm{Si}$ heterojunction was observed using transmission electron microscopy to analyze its crystallographic properties and to reveal atomic profiles at the interface by energy dispersive $\mathrm{x}$-ray spectroscopy. There was a $2 \mathrm{~nm}$ thick transition layer at the heterojunction, where an aligned lattice image from $\mathrm{Si}$ to Ge together with a disordered lattice image could be observed. In the $\mathrm{Si}$ layer close to the interface, islandlike modified regions were observed to exist, where a large amount of Ge was detected. Oxygen was also detected accumulated at the interface. () 2007 American Institute of Physics. [DOI: 10.1063/1.2795797]
\end{abstract}

Ge photodetectors fabricated on Si substrates have recently attracted much attention in Si-based photonic integrated circuits. ${ }^{1,2} \mathrm{Ge}$ crystals have been epitaxially grown on $\mathrm{Si}$ or $\mathrm{SiO}_{2}$. It is difficult, however, to obtain high quality $\mathrm{Ge}$ with sufficient thickness because of the large difference in the lattice constants of Ge and Si. Wafer bonding, or in other words, wafer fusion, is a very easy method for preparing atomically bonded heterojunctions between different materials. $^{3-6}$

Avalanche photodiodes with a wafer bonded InGaAs/Si heterojunction have been proposed to have low multiplication noise properties. ${ }^{7,8}$ Following this idea, we have proposed a $\mathrm{Ge} / \mathrm{Si}$ heterojunction photodiode formed by wafer bonding. ${ }^{9,10}$ In these heterojunction photodiodes, the heterojunction interface properties are very important to determine the device performance, since the devices are operated under a reverse bias voltage, where a very small amount of electronic current flows across the heterointerface. Therefore, heterojunction properties, such as abruptness and uniformity of the interface, and the existence of interface states caused by dislocations, defects, and foreign atoms, may determine device performance. Very few previous reports have discussed direct observations of the heterojunction by transmission electron microscopy (TEM). ${ }^{3,4}$

In this paper, we describe the results of TEM observations of a Ge/Si heterojunction formed by wet wafer bonding. Together with energy dispersive $\mathrm{x}$-ray spectroscopy (EDX), crystallographic properties and Si-, $\mathrm{Ge}$-, and O-atom distributions in the region close to the heterointerface are clarified.

The $\mathrm{Ge} / \mathrm{Si}$ heterojunctions used in this experiment were formed by wet wafer bonding. ${ }^{9}$ After cleaning the Ge and $\mathrm{Si}$ surfaces by degreasing using organic solvents and removing oxidized layers using a HF solution, both surfaces became hydrophilic by dipping the $\mathrm{Si}$ wafer into a solution of $\mathrm{H}_{2} \mathrm{SO}_{4}: \mathrm{H}_{2} \mathrm{O}_{2}: \mathrm{H}_{2} \mathrm{O}$ and the $\mathrm{Ge}$ wafer into a solution of $\mathrm{HCl}: \mathrm{H}_{2} \mathrm{O}$. The two wafers were then brought into contact

\footnotetext{
${ }^{a)}$ Electronic mail: kanbe.hiroshi@kochi-tech.ac.jp
}

with each other in pure water. This sample was then annealed at $880^{\circ} \mathrm{C}$ for $90 \mathrm{~min}$ in a hydrogen atmosphere of $50 \mathrm{~Pa}$ with a pressure of $4 \times 10^{5} \mathrm{~Pa}$ between the two wafers.

The $p$-Si layer used in this work was epitaxially grown on an $\mathrm{Sb}$-doped $n^{+}$-Si substrate. The resistivity of B-doped $p$ $\mathrm{Si}$ is $1.02 \Omega \mathrm{cm}$ with a nominal thickness of $0.95 \mu \mathrm{m}$. Ge is a bulk crystal with $4 \Omega \mathrm{cm}$ resistivity and $400 \mu \mathrm{m}$ thickness. Surface orientations of both wafers are $(100) \pm 1.0^{\circ}$. The sizes of Si- and Ge-wafers were $5 \times 5$ and $6 \times 6 \mathrm{~mm}^{2}$, respectively.

$\mathrm{Ge} / \mathrm{Si}$ heterojunction photodiodes with mesa structure were fabricated using the wafer bonded $\mathrm{Ge} / \mathrm{Si}^{9}$. The fabrication process, which includes polishing and mesa etching, revealed that the percentage of the bonded area is supposed to be almost $100 \%$ for bonded wafers. Photocurrent dependence on the reverse bias voltage for three photodiodes at a wavelength of $1.55 \mu \mathrm{m}$ are shown in Fig. 1. The photocurrent of a commercially available InGaAs/InP avalanche photodiode is also shown for comparison. The incident optical powers for each diode are different. The photocurrent begins to increase at a bias voltage at which the depletion layer reaches the heterointerface. When a higher bias voltage is

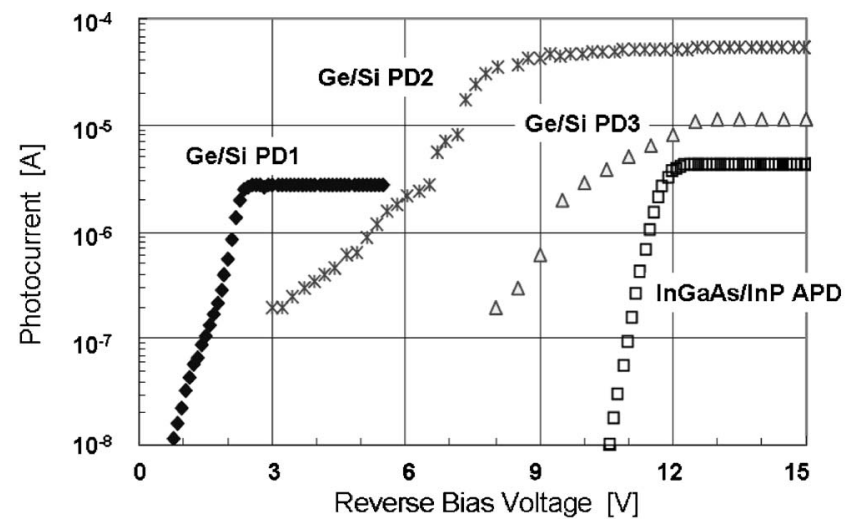

FIG. 1. Photocurrents of three different Ge/Si photodiodes as a function of reverse bias voltage at $1.55 \mu \mathrm{m}$. For comparison, the photocurrent of a commercially available InGaAs/InP avalanche photodiode is shown. 


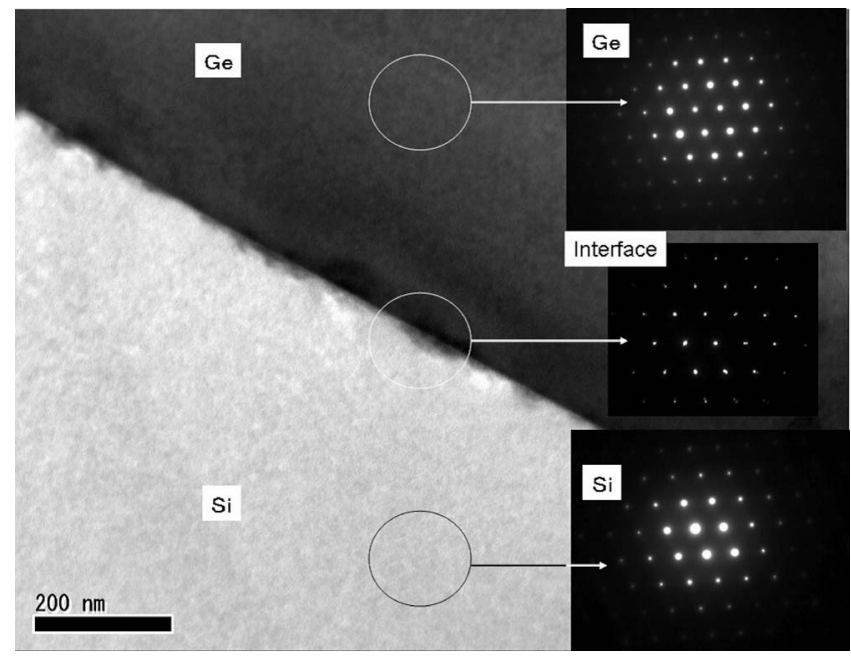

FIG. 2. A bright field TEM photograph of a Ge/Si heterojunction and selected-area diffraction patterns from different positions indicated by circles.

applied to expand the depletion layer into the Ge layer or the InGaAs layer, the photocurrent saturates. The behavior of the rising photocurrent is considered to be related to the properties of the heterointerface boundary. In contrast to the case of the InGaAs/InP photodiode having a very sharp photocurrent change, gradual increase with steps in photocurrents can be seen for the Ge/Si photodiodes. This indicates that the interface is not uniform in the heterojunction area and/or a kind of transition layer exists between $\mathrm{Si}$ and $\mathrm{Ge}$. The quality of the $\mathrm{Ge} / \mathrm{Si}$ heterojunction, such as crystallographic transition, existence of dangling bonds, and interface states, may affect device performance, especially for the photocurrent properties.

We directly observed the Ge/Si heterointerface using TEM. Figure 2 shows a bright field TEM photograph of a $\mathrm{Ge} / \mathrm{Si}$ heterointerface, observed from the [110] direction of $\mathrm{Si}$, and selected-area diffraction (SAD) patterns for the positions indicated by circles. The lower bright region is $\mathrm{Si}$ in the TEM photograph. The upper dark region is Ge, whose [110] direction is tilted about $0.2^{\circ}$ from the [110] Si crystal axis. In the TEM photograph, we can observe islandlike, slightlydark regions in the $\mathrm{Si}$ side with several tens of nanometers thick, as measured from the interface, and 100-200 nm long along the interface. We hereafter refer to these as modified regions.

The upper SAD pattern is for Ge and the lower one is for $\mathrm{Si}$. The SAD patterns from $\mathrm{Ge}$ and $\mathrm{Si}$ far from the interface show very clear diffraction patterns for a diamond structure through the [110] direction. At the Ge/Si heterointerface, however, as shown in the middle SAD pattern, we can see double spots corresponding to both the Ge and Si crystals. This means that there is the possibility of the existence of mixed crystals of separate Ge and Si crystals, as well as GeSi compounds.

High-resolution TEM photographs in the vicinity of the heterointerface are shown in Fig. 3. In Figs. 3(a) and 3(b), the interface is seen as a white band with a thickness of about $2 \mathrm{~nm}$. Also, in the Si side, islandlike dark regions (modified regions) are clearly observed. In the modified region, we can see crystal images, as shown in Figs. 3(b) and 3(c); however, some parts of the crystal array are disordered. In another part, we observe dislocations along the [111] direction. This
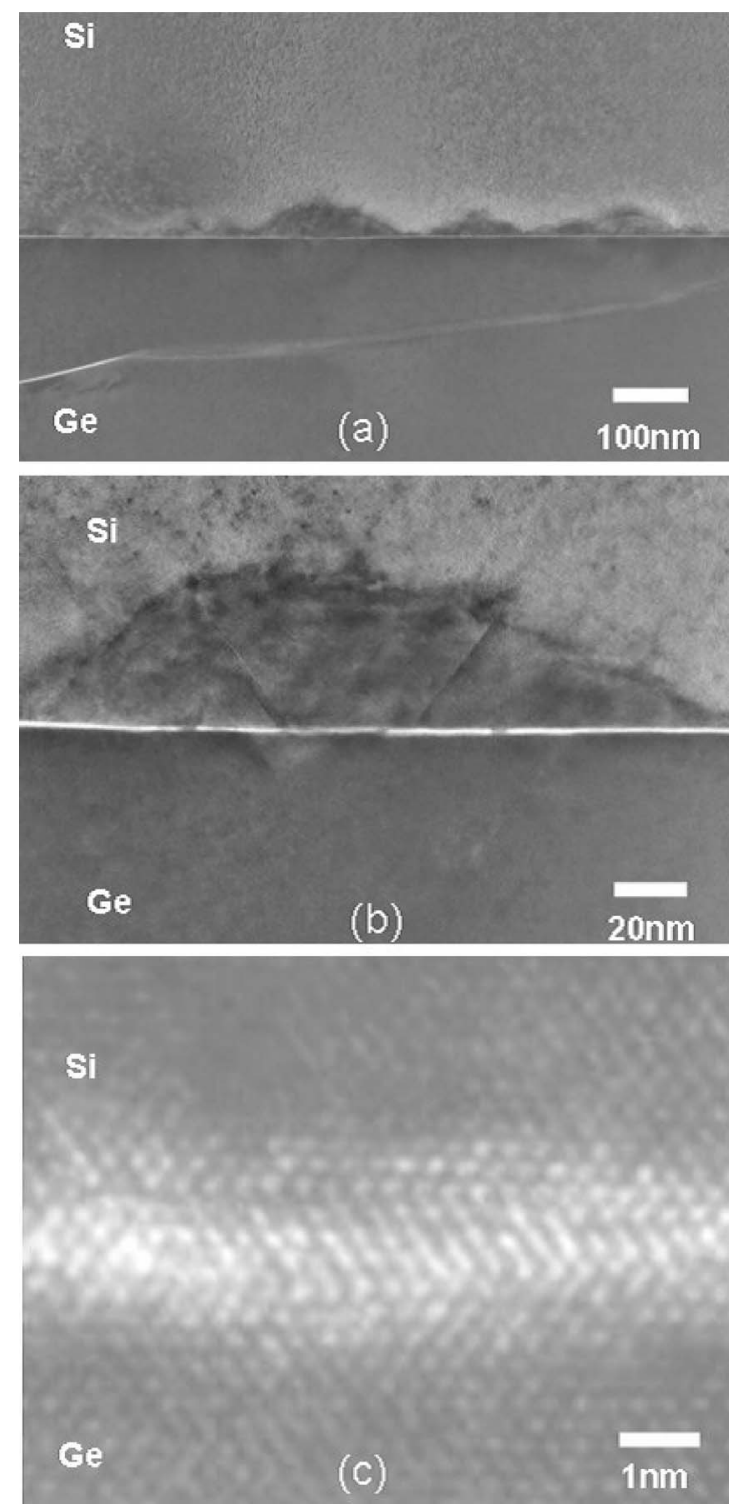

FIG. 3. High-resolution TEM photographs for a Ge/Si heterojunction.

is caused by the relaxation of the large difference in the lattice constants of $\mathrm{Ge}$ and $\mathrm{Si}$.

An enlarged photograph near the heterointerface is shown in Fig. 3(c). The lattice image for both $\mathrm{Si}$ and $\mathrm{Ge}$ can be observed. Note that both crystals are aligned in the same direction of [110]. This result is slightly surprising because the crystallographic directions of both wafers are not precisely aligned when making contact in the bonding process. Both crystallographic directions were automatically aligned in the (110) surface at an angle smaller than $1^{\circ}$. Also in Fig. 3(c), we can see the continuously aligned lattice from the $\mathrm{Si}$ crystal to the Ge crystal in some parts, even though the lattice lines are slightly tilted. In other parts, however, disordered lattice (amorphouslike) images can be observed. From these TEM lattice images, any kinds of dislocation are not observed in the region far from the heterointerface. The stress caused by the large lattice mismatch (about 4\%) between $\mathrm{Si}$ and $\mathrm{Ge}$ is considered to be relaxed by the mixing of $\mathrm{Ge}$ and $\mathrm{Si}$ in the vicinity of the heterointerface within several tens of nanometers.

Figure 4 shows the distributions of $\mathrm{Ge}, \mathrm{Si}$, and $\mathrm{O}$ atoms across the heterointerface (line scanning), revealed by EDX. 

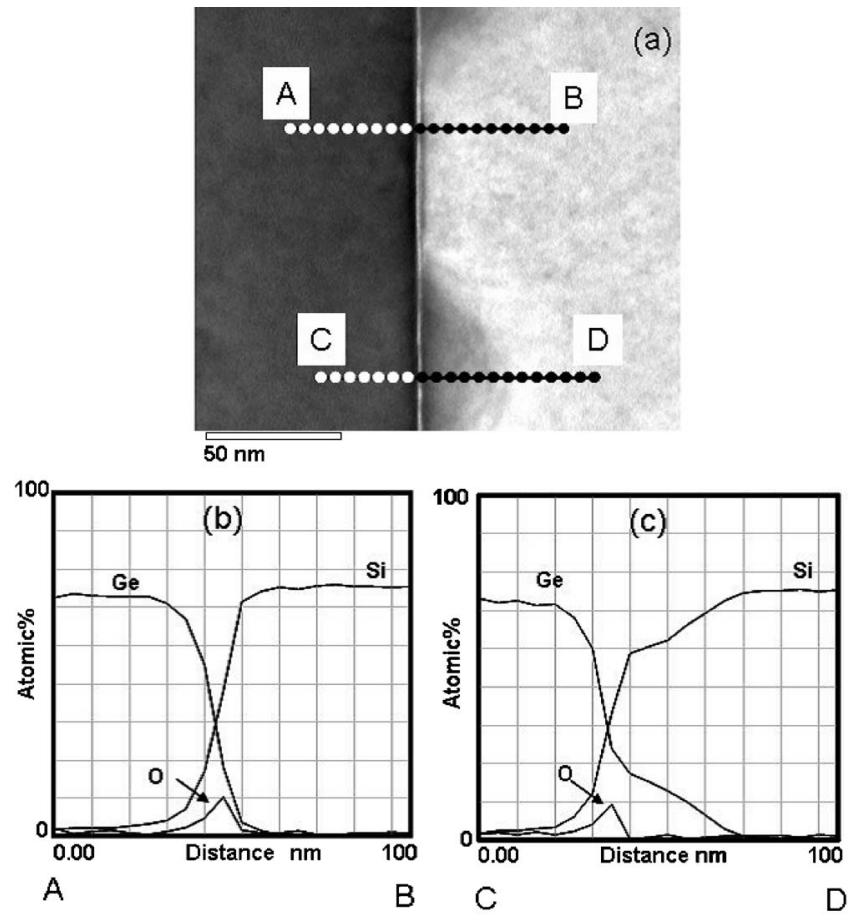

FIG. 4. Ge, $\mathrm{Si}$, and $\mathrm{O}$ atom distributions in the lines shown by A-B (b) and C-D (c) shown in the TEM photograph (a).

In Fig. 4(b), the distributions of these atoms are shown at the positions indicated by the circles A-B in the TEM photograph (a), wherein the modified dark region is not observed in the $\mathrm{Si}$. The distribution of $\mathrm{Ge}$ atoms and $\mathrm{Si}$ atoms is rather sharply changed at the heterointerface. Figure 4(c) shows the profile of the same atoms at the positions of C-D, where the modified dark region exists in $\mathrm{Si}$. In this region, a large amount of $\mathrm{Ge}$ atoms were detected, with a relative lack of $\mathrm{Si}$ atoms. This means that $\mathrm{Ge}$ enters the Si layer to a thickness of about $40 \mathrm{~nm}$, and that the modified regions are mixed with $\mathrm{Ge}$ and $\mathrm{Si}$. Two-dimensional mapping also shows that $\mathrm{Ge}$ distributes in the modified regions. Note that an accumulation of $\mathrm{O}$ atoms with about 10 at. $\%$ at the heterointerface can be seen in both distributions of (b) and (c).

According to the explanation for the mechanism of wafer bonding between hydrophilic surfaces, ${ }^{4}$ the hydroxyl group on the surface contributes to the bonding of wafers by hydrogen bonds when the wafers are in contact. The hydrogen and oxygen in the hydroxyl group are removed from the surfaces and diffuse through the substrates during the annealing. The diffusion constants of hydrogen and oxygen in $\mathrm{Si}$ and $\mathrm{Ge}^{11,12}$ are sufficiently large to have a diffusion length of several micrometers by annealing at $880{ }^{\circ} \mathrm{C}$ for $90 \mathrm{~min}$. The observed $\mathrm{O}$ accumulation at the heterointerface, as shown in Fig. 4, is caused by the binding of $\mathrm{O}$ with $\mathrm{Si}$ and $\mathrm{Ge}$ to form oxidized compounds, during dipping in water before the contact of wafers, and/or during the annealing. The lattice image in Fig. 3 indicates that the atomic lines are randomized at the interface by the existence of such compounds.

The reported diffusion constant of $\mathrm{Ge}$ in $\mathrm{Si}$ is on the order of $10^{-18} \mathrm{~cm}^{2} / \mathrm{s}$ at $880{ }^{\circ} \mathrm{C}$. ${ }^{11}$ This means that the calculated diffusion length for $90 \mathrm{~min}$ annealing is several nanometers. However, the modified region thickness observed in the Si layer at the heterointerface is about $40 \mathrm{~nm}$. The transport of $\mathrm{Ge}$ into $\mathrm{Si}$ is partially caused by surface/interface diffusion with a diffusion constant larger than that of the volume diffusion due to the tensile stress existing in the $\mathrm{Si}$, resulting in the intermixing of $\mathrm{Ge}$ and $\mathrm{Si}$ to relax the stress. In contrast, the $\mathrm{Si}$ diffusion constant in $\mathrm{Ge}$ is on the order of $10^{-13} \mathrm{~cm}^{2} / \mathrm{s}$, ${ }^{12}$ which is much higher than that of Ge in Si. As a result, a very small amount of $\mathrm{Si}$ could be observed in the Ge layer.

In conclusion, we directly observed a wafer-bonded $\mathrm{Ge} / \mathrm{Si}$ heterojunction by transmission electron microscopy and energy dispersive $\mathrm{x}$-ray spectroscopy. In high resolution TEM images, the transition layer between $\mathrm{Si}$ and $\mathrm{Ge}$ was observed with a thickness of $2 \mathrm{~nm}$, where the $\mathrm{O}$ atoms accumulated. Atomically aligned parts and disordered parts were seen at the heterointerface. With a thickness of $40 \mathrm{~nm}$ from the heterointerface, a modified region was seen in the $\mathrm{Si}$ layer wherein a large amount of Ge was detected. This thickness of Ge penetration cannot be explained by simple diffusion. These crystallographic results need to be compared with the electrical properties of the Ge/Si heterojunction for future work.

The authors would like to thank M. Kumon for his contribution to the wafer bonding technique, and S. Mizuno and H. Takahata at NTT-AT for their TEM observation efforts.

${ }^{1}$ S. J. Koester, J. D. Schaub, G. Dehlinger, and J. O. Chu, IEEE J. Sel. Top. Quantum Electron. 12, 1489 (2006), also the papers in this issue.

${ }^{2}$ L. C. Kimerling, Appl. Surf. Sci. 159-160, 8 (2000).

${ }^{3}$ Y. H. Lo, Z. H. Zhu, Y. Qia, F. E. Ejeckam, and G. L. Christenson, Proc. SPIE 3006, 26 (1997).

${ }^{4}$ Q.-Y. Tong and U. Gösele, Semiconductor Wafer Bonding: Science and Technology (Wiley, New York, 1999).

${ }^{5}$ D. Pasquariello and K. Hjort, IEEE J. Sel. Top. Quantum Electron. 8, 118 (2002).

${ }^{6}$ A. Black, A. R. Hawkins, N. M. Margalit, D. I. Babic, A. L. Holmes, Jr., Y. L. Chang, P. Abraham, J. E. Bowers, and E. L. Hu, IEEE J. Sel. Top. Quantum Electron. 3, 943 (1997).

${ }^{7}$ A. R. Hawkins, T. E. Reynolds, D. E. England, D. I. Babic, M. J. Mondry, K. Streubel, and J. E. Bowers, Appl. Phys. Lett. 68, 3692 (1996).

${ }^{8}$ Y. Kang, P. Mages, A. R. Clawson, P. K. L. Yu, M. Bitter, Z. Pan, A. Pauchard, S. Hummenl, and Y. H. Lo, IEEE Photonics Technol. Lett. 14, 1593 (2002).

${ }^{9}$ H. Kanbe, M. Komatsu, and M. Miyaji, Jpn. J. Appl. Phys., Part 2 45, L644 (2006).

${ }^{10} \mathrm{H}$. Kanbe, The 19th Annual Meeting IEEE LEOS, Montreal, November 2006 (unpublished), Paper No. ThQ3.

${ }^{11}$ Semiconductors, Landolt-Borstein, New Series, Group III, Vol. 17, edited by O. Madelung, M. Schulz, and H. Weiss (Springer, Berlin, 1984), pp. 494-495.

${ }^{12}$ Semiconductors: Basic Data, 2nd ed., edited by O. Madelung (Springer, Berlin, 1996), p. 38. 